\title{
BIOLOGICAL AND ECOLOGICAL CHARACTERISTICS OF SOFT TICKS (IXODIDA: ARGASIDAE) AND THEIR IMPACT FOR PREDICTING TICK AND ASSOCIATED DISEASE DISTRIBUTION
}

\author{
VIAL L.*
}

\section{Summary:}

As evidence of global changes is accumulating, scientists are challenged to detect distribution changes of vectors, reservoirs and pathogens caused by anthropogenic and/or environmental changes. Statistical and mathematical distribution models are emerging for ixodid hard ticks whereas no prediction has ever been developed for argasid ones. These last organisms remain unknown and under-reported; they differ from hard ticks by many structural, biological and ecological properties, which complicate direct adaptation of hard tick models. However, investigations on bibliographic resources concerning these ticks suggest that distribution modelling based on natural niche concept and using environmental factors especially climate is also possible, bearing in mind the scale of prediction and their specificities including their nidicolous lifestyle, an indiscriminate host feeding and a short bloodmeal duration, as well as a flexible development cycle through diapause periods.

KEY WORDS : Argasidae, soft tick, Ornithodoros, biology, ecology, geographical distribution, natural niche, predictive modelling
Résumé : CARACTÉRISTIQues BIOLOGIQUes ET ÉCOLOGIQUeS DES TIQUES MOLLES (IXODIDA: ARGASIDAE) ET IMPLICATIONS QUANT À LA PREDICTION DE LEUR DISTRIBUTION ET DES MALADIES ASSOCIÉES

Dès lors que des preuves du changement global s'accumulent, les scientifiques se doivent de détecter les changements de distribution de vecteurs, de réservoirs et de pathogènes causés par des modifications anthropogéniques ou environnementales. Alors que des modèles de distribution statistiques ou mathématiques, commencent à émerger pour les tiques dures (ixodidés), aucune prédiction n'est disponible pour les tiques molles (argasidés). Ces organismes restent inconnus et sous-estimés; ils diffèrent des tiques dures par leurs propriétés structurales, biologiques et écologiques, qui compliquent la simple adaptation de modèles initialement développés pour les tiques dures. Toutefois, l'étude des données bibliographiques concernant ces tiques suggère qu'il est possible de prédire leur distribution basée sur le concept de niche naturelle en fonction de variables environnementales essentiellement climatiques. Il est alors nécessaire de choisir correctement l'échelle d'étude et de considérer leurs spécificités incluant leur statut nidicole, leur opportunisme pour les hôtes et la faible durée de gorgement sur hôte, ainsi que la flexibilité du cycle de développement par l'entrée en diapause.

MOTS CLÉS : Argasidae, tique molle, Ornithodoros, biologie, écologie, distribution géographique, niche naturelle, modélisation prédictive.

tors and reservoirs of pathogens (Jonjegan \& Uilenberg, 2004). Illustrations of the diseases transmitted by soft ticks include: 1) human tick-borne relapsing fever (TBRF) transmitted worldwide by Ornithodoros ticks and caused by spirochetes of the genus Borrelia, 2) viral encephalitis transmitted by ticks infesting seabirds, shore birds and roosting birds, 3) the african swine fever virus (ASFV) transmitted by O. moubata and O. porcinus in Africa, 4) fowl spirochetosis or anaplasmosis-like infections caused by B. anserina and Aegyptianella pullorum, respectively, and transmitted by Argas persicus worldwide, and 5) epizootic bovine abortion caused by B. coriaceae and transmitted by O. coriaceus in North America. Argasid ticks of recognized medical and veterinary importance typically belong to the genera Argas, Ornithodoros and Otobius (Jonjegan \& Uilenberg, 2004). As evidence of global climate change accumulates (Intergovernmental Panel on Climate Change, synthesis report, 2007: http://www.ipcc.ch/ipccreports/ar4-syr.htm), so does recognition of its potential consequences for human and animal health. Scientists are challenged to 
detect changes in the distribution of vectors, reservoirs and pathogens, and to attribute these shifts to anthropogenic and/or environmental changes (McMichael et al., 2006). As a consequence, it is essential to reveal any of biological and ecological characteristics of soft ticks, in contrast to those of the ixodid line, to understand their peculiar distribution patterns and habitat preferences and their specific role as parasites, vectors and pathogen reservoirs (Hoogstraal, 1985; Sonenshine, 1993).

The present paper aims $i$ ) to review such characteristics of soft ticks, with a special emphasis on the genus Ornithodoros; $i$ i) to present their epidemiological impact in terms of risk for tick and associated disease distribution; and iii) to propose new research priorities to improve model predictions on changes in the distribution of soft ticks and tick-borne diseases.

\section{BIOLOGICAL AND ECOLOGICAL CHARACTERISTICS OF SOFT TICKS}

\section{NidiCOLOUS LIFESTYLE}

The peculiar nature of oilskin and cement components of argasid ticks' cuticle makes it highly resistant and reduces water evaporation, allo- wing soft ticks to survive at high temperatures and under relatively dry conditions (Lees, 1947). For example, O. moubata and O. savignyi tolerate air temperature up to $63^{\circ} \mathrm{C}$ and $75^{\circ} \mathrm{C}$, respectively (Morel, 1969). This phenomenon results in the common presence of soft ticks in tropical and subtropical zones and their spread into arid areas of Central Asia and Africa (Sahara) (Morel, 1969).

However, the success of their developmental cycle depends on cooler conditions, which are provided by the sheltered microhabitats they colonize. Most argasid ticks are nidicolous living in the nests, burrows, and caves of vertebrate animals or in human and livestock habitations, where they survive in cracks, crevices, under rock ledges, among nest fibres, or in sandy, rocky, or dusty ground surface (Sonenshine, 1993). Some, known as endophilous nidicoles like many Ornithodoros tick species (Figs 1A, B, C, D) live inside these microhabitats while geophilous nidicoles prefer harborages nearby host habitations. In addition to intrinsic microclimatic conditions of shelters, body heat and moisture from the respiration and excrement of the host within the microhabitat help establish the atmospheric conditions required for the development of these ticks (Sonenshine, 1993). Soft ticks show strict, narrowly defined temperature and humidity tole-
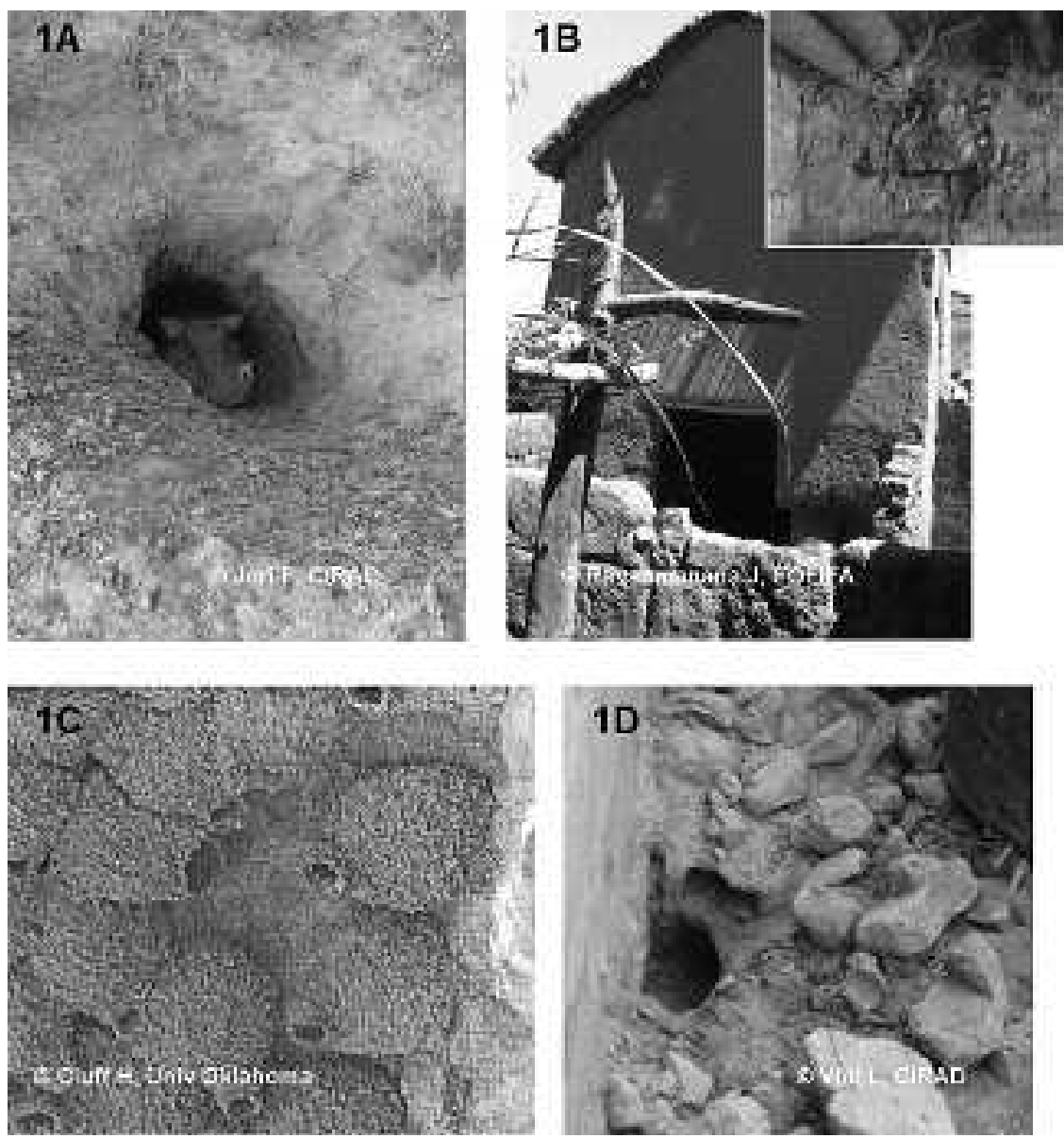

Fig. 1. - Examples of typical microhabitats for endophilous Ornithodoros soft ticks, including (1A) warthog burrows infested by $O$. moubata spp. in Mozambique, (1B) crevices colonized by $O$. porcinus domesticus and opening inside human and pig buildings in Madagascar, (1C) mud nests of rocky cliff swallows inhabited by $O$. concanensis in the United-States, or (1D) rodent burrows infested by $O$. sonrai and opening inside human houses in Senegal. 
rances for development and activity, reflecting the conditions of their microhabitat. These optima are distinct for closely related species and may be so specific as to be included in the species definition (Morel 1969).

\section{DeVElopmental CyCle}

In contrast to ixodid ticks, soft ticks present many nymphal instars (2-8) between the larval and adult stages (Fig. 2). Each immature stage requires at least one bloodmeal on a vertebrate host prior to moulting, except larvae of some Ornithodoros species like O. moubata (Fig. 2). The number of nymphal moults varies from two to nine according to species; the quality and the amount of blood ingested also influence this number (Morel, 1969). When emerging, soft tick adults are longlived, with a maximum life span as great as 25 years for some species (Sonenshine, 1993), and are able to feed several times when hosts are available (1-10) (Morel, 1969). In argasid females, each bloodmeal is generally followed by egg laying, with or without a previous copulation because females are able to retain sperms within endospermatophores (Fig. 2). Compared to hard ticks, soft tick clutches are small (5-500) but, a given female can produce from two to five clutches over her lifetime. This iteroparous strategy could be seen as an adaptation to host scarcity and/or climatic variability; however, even with multiple clutches, soft ticks never achieve the amount of eggs produced by some ixodid ticks (Morel, 1969).

Regarding this aspect, as well as the multiplicity of nymphal instars, the life-cycle of a soft tick could be considered less efficient than that of a hard tick. However, its total duration may be optimized thanks to short pre- and post-feeding delays, as well as short moulting periods and rapid feeding (see below). Set apart from possible interrupted seasonal development, Argas persicus or Otobius megnini showing only 2-3 nymphal instars complete their development in 49-118 days, whereas more O. moubata and O. porcinus, with 4-7 nymphal instars require 76-155 days. Developmental cycles of 80-120 days for one-host hard ticks like Boophilus microplus or of 80-300 days for three-host hard ticks like Dermacentor andersoni or Amblyomma americanum are usually reported (Loomis, 1961; Morel, 1969). Regardless of interspecific variability, the global duration and success of the developmental cycle of soft ticks depend on the efficiency of blood feeding and on climatic conditions. High to significantly high effects of temperature and humidity are noticed on mean egg incubation period and hatching success, larval and nymphal prefeeding/premoulting durations and adult preoviposition/oviposition duration (Cunliffe, 1921; Wheeler, 1943; Loomis, 1961; Hafez et al., 1971; Balashov, 1972; El Shoura, 1987; Endris et al., 1991; Olmedo et al., 1995).

\section{BLOOD FEEDING}

A major characteristic of soft ticks is the short duration of bloodmeal, particularly for nymphs and adults (15-60 minutes). The duration is typically longer for larvae (12 hours to several days) (Fig. 2). This feature

Fig. 2. - A typical life-cycle of a soft tick indicating the different developmental instars, the crucial steps between instars and, in grey boxes, the duration of each step for the species O. moubata (according to Morel, 1969; Cunliffe, 1921; Loomis, 1961).

\section{Adult bloodmeal: 15-60 min}

Number of adult bloodmeals: 1-10

No moulting for $O$. moubata adults

Duration feeding-oviposition: 13 days [7-24]

Several laying outs after a single copulation 1 bloodmeal for each laying bout Number of eggs/bloodmeal: 111 [28-318] Number of eggs/female: 350 [108-488]
For each nymphal instar: Emergence to feeding: 3 days [1-7] Nymphal bloodmeal: $15-60$ min Nymphal moulting: 11 days [8-13] Number of nymphal instars: 4-7 
may be seen as an adaptation to their nidicolous lifestyle; they reduce possible exposure to unfavourable external conditions by detaching rapidly from their vertebrate hosts before these hosts leave the microhabitat in search of food or a sexual partner (Sonenshine, 1993). Soft ticks have developed physiological strategies to favour such rapid blood feeding, including high tegument distension during blood feeding and excretion of excess water and ions via coxal glands as soon as blood is ingested or just after detachment (Hoogstraal, 1985). Many pathogens maintained in soft tick reservoirs like Borrelia or ASFV are excreted in coxal fluid, which increases their transmission capacity through tick-to-tick transfers (Gaber et al., 1984; Kleiboeker et al., 1998).

Soft ticks are commonly polyphagous, that is changing host for each bloodmeal, except for some species like Ot. megnini where larvae and nymphs engorge and moult on the same ungulate (Morel, 1969). Argasid ticks seem to exhibit varying degrees of host preference, ranging from strict specificity, as for certain bat-parasitizing tick species of the genera Ornithodoros, Antricola, Nothoaspis, Carios, Chiropterargas or Secretargas, to little or no described specificity for burrow-inhabiting endophilous Ornithodoros species (Sonenshine, 1993). Indeed, it has been suggested that most soft ticks actually show indiscriminate host feeding and that apparent variation in host preference likely reflects microhabitat preference and host availability within the microhabitat (Morel, 1969). As a consequence of their nidicolous lifestyle, soft ticks may simply choose hosts that are directly available in their favourable microhabitat, resulting in an apparent selection of small vertebrate hosts, domestic livestock and humans. However, host preferences are difficult to investigate in soft ticks because they feed rapidly and are thus difficult to find on the host; only PCR amplification of host genes within tick midgut may allow us to detect such relationships (Kent, 2009).

Indiscriminate host feeding was clearly demonstrated for some Ornithodoros tick species, including: i) O. tartakovskyi transmitting TBRF in Central Asia and able to feed on terrapin, skink, agama, gecko, sand snake, toad, hedgehog, dog, mouse, bee-eater, roller and sparrow (Vasil'eva, 1971); ii) O. verrucosus and O. alactagalis in Soviet Georgia that feed on tortoise, snake, toad, burrow-inhabiting bird, fox and bird, rodent, fox, respectively (Gughusvili 1980); iii) O. sonrai in Senegal, which is able to feed on many rodent and insectivore species that are naturally infected by TBRF (Trape et al., 1996) and which occasionally feeds on pigs living close to small mammal burrows and is thus contaminated by ASFV (Vial et al., 2007), iv) O. moubata spp. transmitting TBRF in Tanzania that is able to feed on pigs and chickens, and which has been recently found infected by $B$. duttonii in a region where no animal reservoir is known (McCall et al., 2007).

\section{SEASONAL POPULATION DYNAMICS}

As a possible adaptation to a nidicolous lifestyle and host scarcity, argasid ticks, especially adults, are very resistant to starvation for several years and are able to enter a quiescent phase for two to eight months (Morel, 1969). Seasonal morphogenetic diapause is usually correlated to host availability and delays developmental activity such that the expansion of the tick population is optimized during the seasonal period when hosts are present (Sonenshine, 1993). However, host seeking activity is not directly affected by this diapause. For example, O. kelleyi feeds seasonally during the spring on bats returning from winter caves to abandoned buildings or cracks infested by ticks; these ticks, collected in winter when bats are absent, feed readily when offered these hosts in laboratory (Sonenshine \& Anastos, 1960). In Egypt, A. arboreus infesting the nests of herons and other roosting birds delays oviposition until the following spring when it feeds during the fall, but oviposits without delay when it feeds in July (Khalil, 1974; Khalil \& Shanbaky, 1976). Conversely, soft ticks infesting nest or burrows of non-migratory hosts are not considered to exhibit seasonal activity, especially when they are indiscriminate feeders (Sonenshine, 1993). In many cases, this may be due to the fact that these ticks inhabit microhabitats where climatic conditions are buffered all along the year (Sonenshine, 1993). However, diapause remains an inherent attribute of the biology of many nidicolous ticks and seasonal climate changes can impact feeding activity and the consequent reproductive and developmental cycle (Morel, 1969). Nevertheless, such patterns are most often observed at the geographic limits of the species' distribution, in temperate or sub-Saharan areas where ticks carry out feeding or ovipositional diapause during winter or dry season, and not at the center of the distribution in tropical or subtropical areas. For example, O. tholozani from Central Asia does not feed on cattle during winter and shows a diapause of six months, while the same species is active during the whole year in Israel (Moskvin, 1927; Avivi, 1967). Similar observations have been reported in Spain for O. erraticus that does not feed on its common pig host until pigpens reach a temperature of $13-15^{\circ} \mathrm{C}$ (Oleaga-Perez et al., 1990). In Egypt, the same species (actually its small variant $O$. sonrai) inhabiting rodent burrows shows the highest densities of adults during the summer and early fall and the lowest during the winter months, suggesting a seasonal decline in successful feeding and moulting. The rodent hosts in this area have been found in burrows throughout the year (Khalil et al., 1984). 


\section{PREDICTIONS ON SOFT TICK AND DISEASE DISTRIBUTION}

\section{THE CONCEPT OF THE NATURAL NICHE}

$\mathrm{P}$ redictions of vector and vector-borne disease occurrence are based on two major concepts: 1) the natural nidality of transmissible diseases meaning that, independent of humans, infectious diseases exist in nature under a combination of local conditions and in the presence of vertebrates and arthropods that act as vectors and/or reservoirs of the pathogenic agent (Pavlovsky, 1966), and 2) the fundamental ecological niche of a species, defined as a set of environmental conditions within which a species can survive and persist. This niche consists of an "n-dimensional hypervolume" that determines suitable habitat for the species but is distinct from the distribution of the species plotted in the geographical space (Hutchinson, 1957). Under the first concept, and provided strict assumptions on disease transmission dynamics, it is possible to approximate disease distribution using some indices, such as those based on vector presence and/or abundance. According to the second concept, such potential vector presence and/or abundance should be predicted instead of being described, in order to extend predictions into non sampled areas or future periods. This method uses habitat suitability based on favourable or tolerable environmental conditions for a species survival, development and dynamics.

\section{RELEVANT CHARACTERISTICS OF SOFT TICKS TO PREDICT THEIR NICHE}

Considering the peculiar biology and ecology of argasid ticks, it seems difficult to adapt predictions of suitable habitats for hard ticks to soft ticks. The major feature that often discriminates these groups of organisms in relation to their environment is the nidicolous lifestyle of argasid ticks. These ticks, especially endophilous ones, are limited to specialized niches and have developed well-adapted life history traits that insure their persistence in their microhabitat. For example, the short blood feeding period for nymphs and adults may result in low dispersal capacity, or at least "step by step" dispersion, and thus in a more limited distribution of soft tick species and their associated pathogens (Sonenshine, 1993). Such patterns have been illustrated by different field and experimental studies: i) in Madagascar, O. p. domesticus was present over an eight year period (2000-2008) at the same pig barn, but was absent in neighbouring farms at both sampling occasions (Ravaomanana, personal communication). Natural infection by ASFV was still detectable in ticks in 2008 whereas no potentially infected pig had been introduced to the barns since 2004 (Vial, personal communication); ii) in Senegal, O. sonrai was present in 1991 and 2002 in same human buildings of Dielmo village, and corresponded to two permanently positive clusters of disease transmission (significantly more TBRF cases detected in humans throughout the study period) (Vial, 2005; Vial et al., 2006a); iii) for O. tartakovskyi ranging from Turkmenia to Kazakhstan and O. erraticus with its large variant in North Africa and its small one in West Africa (renamed O. sonrai), a positive correlation has been obtained between decreased fertility or complete sterility and the geographical distance between cross-bred tick populations (Chabaud, 1954; Balashov, 1971), suggesting low or insignificant gene flow between natural populations within a described species range.

Being nidicolous, especially endophilous, consists of adding an intermediate environmental layer between the external conditions outside the microhabitat, readily measurable and commonly used for species distribution models (e.g. air temperature, air humidity and evaporation, sunshine, wind, altitude, hydrography, landscape and land use), and the internal conditions of the microhabitat that directly influence soft tick survival, development and dynamics (e.g. temperature, moisture, darkness, host presence). Internal conditions depend on external ones, but the specific organization of the microhabitat and the structure of the intermediate layer (e.g. depth and width of the opening, nature and size grading of soil, etc.) buffer outside conditions. This buffering effect should be taken into account for soft tick distribution models. For instance, a few studies have investigated the relationships between the internal and external conditions of different microhabitats inhabited by endophilous ticks or closely-related arthropods, but it is already possible to extract some general patterns (Table I). Niche temperature and relative humidity usually show lower amplitude than outside air conditions, determining the lower and upper limits of optimal conditions for tick survival and development. According to the spatial scale considered, the influence of landscape, hydrography and anthropogenic activities on the organisation of the microhabitat and the structure of the intermediate layer will be more or less important for predictions. At regional scale, as for hard ticks, it is possible to consider that most distribution patterns can be extracted from climatic conditions (Cumming, 2002), except at range margins where the presence of rivers or mountains may change the microclimate and allow the presence of soft ticks in seemly unsuitable habitats. Conversely, at local scale, differences in the distributional patterns may depend mainly on pedology, hydrography, landscape composition or organization, and vegetation. For example, Ornithodoros species belonging to the now obsolete group Theriodoros Pospelova-Shtrom 1953, are located in dif- 


\begin{tabular}{|c|c|c|c|c|}
\hline Authors & Climatic zone & Microhabitat & $\begin{array}{l}\text { Arthropod } \\
\text { species }\end{array}$ & $\begin{array}{c}\text { Temperature } \\
\text { and humidity relationships }\end{array}$ \\
\hline \multirow[t]{2}{*}{$\begin{array}{l}\text { Pospelova-Shtrom, } \\
1953\end{array}$} & \multirow[t]{2}{*}{$\begin{array}{l}\text { Temperate continental } \\
\text { climate (Turkmenistan) }\end{array}$} & Gerbil burrow & O. tartakovskyi & 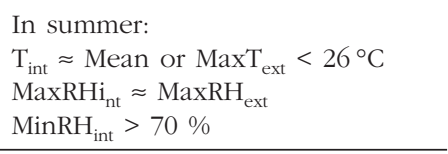 \\
\hline & & Cave (fox den) & O. verrucosus & $\begin{array}{l}\text { Similar moisture deficit but with } \\
\text { lower amplitude inside microhabitat }\end{array}$ \\
\hline Avivi, 1967 & $\begin{array}{l}\text { Temperate mediterranean } \\
\text { climate (Israël) }\end{array}$ & Sand-stone caves & O. tholozani & $\begin{array}{l}\text { In summer: } \\
\mathrm{T}_{\mathrm{int}} \approx \mathrm{MaxT}_{\mathrm{ext}}-[19-20]<26^{\circ} \mathrm{C} \\
\operatorname{MaxRH}_{\mathrm{int}} \approx \mathrm{MaxRH}_{\mathrm{ext}} \\
\text { MinRH }_{\mathrm{int}}>60 \% \\
\text { In winter: } \\
\mathrm{T}_{\mathrm{int}} \approx \operatorname{MinT}_{\mathrm{ext}}+[3-4] \\
\text { MaxRHi }_{\mathrm{nt}} \approx \mathrm{MaxRH}_{\mathrm{ext}} \\
\text { MinRH }_{\mathrm{int}} \approx \operatorname{MinRH}_{\mathrm{ext}}\end{array}$ \\
\hline Butler et al., 1984 & $\begin{array}{l}\text { Temperate to subtropical } \\
\text { oceanic climate (Florida) }\end{array}$ & Gopher-tortoise burrow & O. turicata & $\begin{array}{l}\mathrm{T}_{\mathrm{int}} \approx \mathrm{T}_{\mathrm{ext}}-[4-7]<25^{\circ} \mathrm{C} \\
\mathrm{RH}_{\mathrm{int}} \approx \text { MeanRH }_{\mathrm{ext}}+[40-55]>8 \%\end{array}$ \\
\hline $\begin{array}{l}\text { Yunker \& Guirgis, } \\
1970\end{array}$ & $\begin{array}{l}\text { Sub-saharan desert or } \\
\text { semi-desert (Egypt) }\end{array}$ & Gerbil burrow & Hyalomma spp. & $\begin{array}{l}\text { In summer: } \\
\mathrm{T}_{\mathrm{int}} \approx \mathrm{MaxT}_{\mathrm{ext}}<30^{\circ} \mathrm{C} \\
\mathrm{RH}_{\mathrm{int}} \approx \mathrm{MeanRH}_{\mathrm{ext}}+[30-60]>80 \% \\
\text { In winter: } \\
\mathrm{Ti}_{\mathrm{nt}} \approx \mathrm{MinT}_{\mathrm{ext}}<15^{\circ} \mathrm{C} \\
\mathrm{RH}_{\mathrm{int}} \approx \text { MeanRH }_{\mathrm{ext}}+[30-60]>80 \%\end{array}$ \\
\hline Heger et al., 2006 & $\begin{array}{l}\text { Sub-tropical to tropical } \\
\text { climate (Venezuela) }\end{array}$ & $\begin{array}{l}\text { Wall crack of human } \\
\text { houses }\end{array}$ & Rodnius prolixus & $\begin{array}{l}\mathrm{T}_{\text {int }} \approx \text { MeanT }_{\text {ext }} \\
\text { Ampl } \mathrm{T}_{\text {int }}<<\text { Ampl } \mathrm{T}_{\text {ext }} \\
\text { Similar moisture deficit but with } \\
\text { lower amplitude inside microhabitat }\end{array}$ \\
\hline
\end{tabular}

Table I. - Mathematical relationships (extracted from various studies) linking internal and external temperature and humidity of varied microhabitats inhabited by different endophilous tick species, or closely-related arthropods, in distinct climatic zones.

ferent continents but within the same eco-climatic region showing continental or Mediterranean temperate to sub-tropical climates and vegetation characterized by low grasslands, steppes and semi-deserts (Morel, 1969). All of these species likely colonize rodent or reptile burrows and are directly in contact with soil, which highly depends on the external climate. However, one of these species O. sonrai (formerly O. erraticus small variant) is present in Egypt, despite the fact that global temperature and humidity in most areas of the country seem unsuitable for its survival and development; its presence is mainly due to an equilibrium of sufficiently dry areas and proximity to a water source (the Nile Valley or local oases) that maintains a minimum relative soil humidity inside microhabitats (Hoogstraal et al., 1954). At local scale, pedology is responsible of local heterogeneity, with a high infestation of burrows composed by silt, silt-sand or sand-clay soil and a complete absence of O. sonrai from pure sand situations, even when open to humid sea or river breezes, as well as wet ground of extremely saline areas (Hoogstraal et al., 1954).

Finally, regarding the common indiscriminate host preference lifestyle of many soft ticks, host availability seems to be less important to predict their geographical distribution than for hard tick species. However, at local scale, the nature of the host community may act as an evolutionary driver of tick populations. For example, three genetically distinct tick populations have been detected within the distribution range of $O$. sonrai in Senegal, Mali and Mauritania, using PCR amplifications of the 16S rDNA gene (Vial et al., 2006b). Although no cause has been clearly identified, the geographical distribution of these three clusters apparently corresponded to rodent community zoning, with a predominance of Gerbillinae species associated with group 3 in northern Saharan to Sahelo-Sudanan regions, a predominance of Murinae species associated with group 1 in south-western Senegal, and the presence of Mus musculus in Richard-Toll associated with group 2 (Duplantier et al., 1997).

\section{CURRENT ADVANCES \\ FOR PREDICTING SOFT TICK DISTRIBUTION}

For now, no distributional model has been developed for any argasid tick. The only reference for soft ticks is from Cumming \& Van Vuuren (2006) who modelled continental changes of geographical range for 73 African tick species, dealing with O. moubata and Ot. megnini in the same way as for hard ticks. While results seemed 
conclusive for Ot. megnini that shows life history traits close to exophilous hard ticks, the model could not explain the high variability of $O$. moubata presence data, suggesting an influence of other, still unidentified, environmental factors acting on its distribution. Presence data are available for many species from past field studies and could be used for modelling or as preliminary assessments of soft tick distributions. For example, Morel (1969) devoted part of his career to recording the results of hard and soft tick sampling conducted by various scientists in Africa and Mediterranean Basin starting at the beginning of the twentieth century. For each record, he specified the location, date, host or habitat, stages and verified the identification by observing original specimens if available. These data are available on a CDrom published by CIRAD in 2003 and an example application of this data is given in Figure 3. More recently, the Integrated Consortium on Ticks and Tick-borne Diseases (ICTTD) (http://www.icttd.nl/) proposed to produce and update a worldwide tick presence database associating each record with GPS coordinates and Cumming has already published some data for African ticks (http://www.wec.ufl.edu/faculty/ cummingg/TickDiP.htm). However, such data may show some biases: $i$ ) they essentially correspond to historical data from the 1930s to the 1960s when many field collection campaigns were organized. Since this time distribution patterns may have changed; ii) they may show a bias in sampling because information comes from distinct collectors using different protocols and techniques and samplings may have been done in accessible areas only, for example along the main roads, which is not representative of realized distribution; iii) they only correspond to presence data because some scientists did not document absences or because records come from museum collections where only specimens that were found are stored; iv) they are subjected to misidentification according to the expertise and the sense of responsibility of the collector and because of complexity and ambiguity of the morphological keys used at this period for tick identification. Other available resources on soft tick biology and ecology can be obtained through: $i$ ) field observations of habitat/microhabitat preferences or the seasonal dyna-

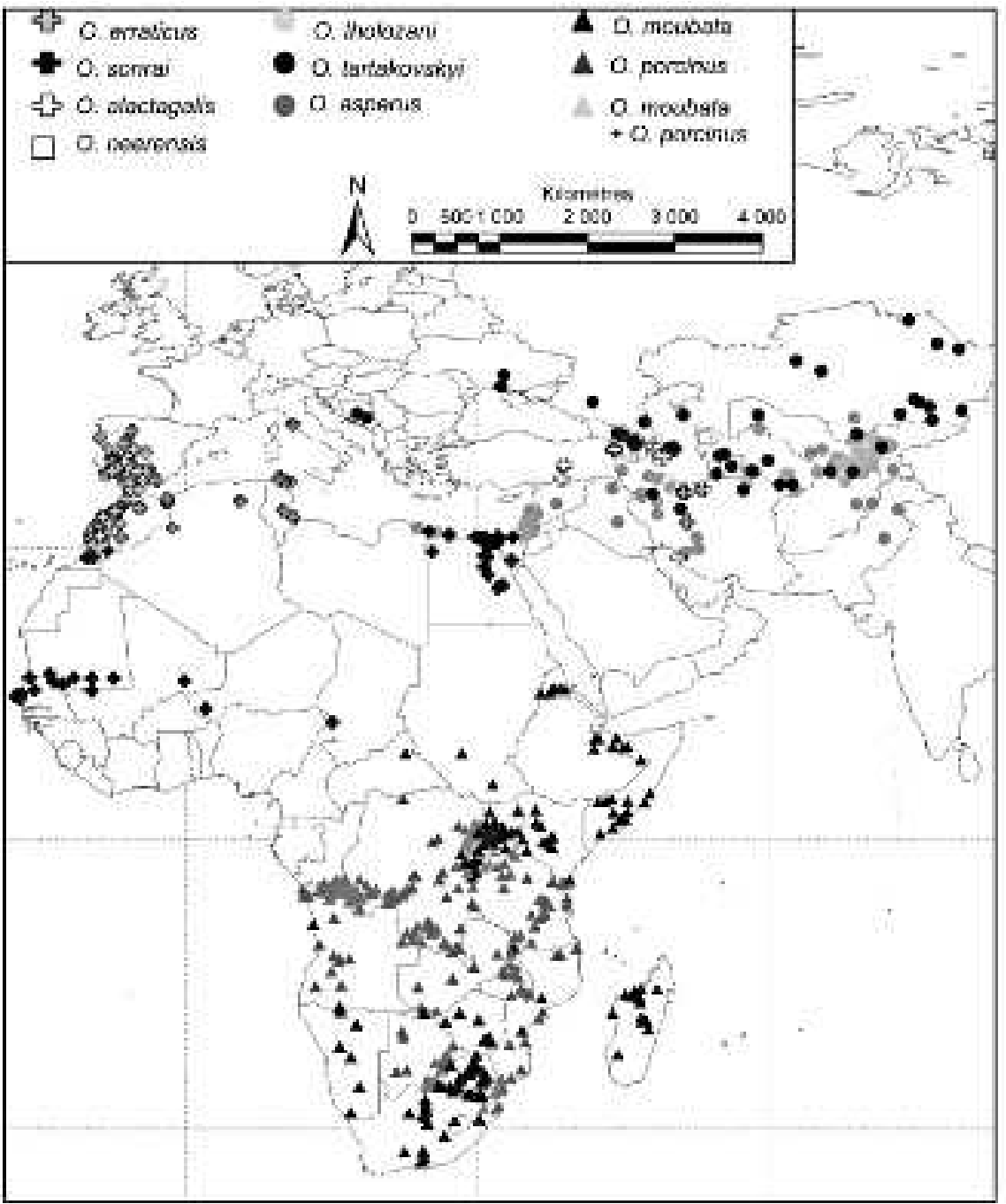

Fig. 3. - Geographical location of Morel's presence data for several species of Ornithodoros ticks transmitting TBRF and/or ASFV in Eurasia and Africa. 1052 records were reported and 865 were geographically localized using the US Army Gazeeter (http://tomcat-dmaweb1.jrc.it/fuzzyg/ query/). 
mics of tick populations; and ii) laboratory experiments investigating the influence of climatic conditions (e.g. temperature, humidity and sunshine) on survival, life cycle and feeding success. Such data may be useful, as a preliminary approach, to predict the possible relationship between geographical range of soft ticks and some environmental factor. For example, the African subgenus Ornithodoros sensu stricto Koch 1944 was highly documented in the 1960s by Walton who clearly demonstrated that $O$. moubata consisted of a complex of species and subspecies, each showing distinct morphological, biological and ecological features (Walton, 1979). His 20 years of intensive research on TBRF in East Africa provided new insights on O.p.domesticus, suggesting the existence of at least four different ecological "races" locally adapted to different regions and presenting distinct temperature and humidity optima (Walton, 1962, 1964, 1979). During the same period, Pierce (1974) investigated O. p. porcinus distributional patterns according to climate, soil, vegetation, host and season. Within the same subgenus, the biology of O. moubata sensu stricto from Southern Africa was investigated in the laboratory by Cunliffe (1921), Jobling (1925) and Loomis (1961) according to temperature and humidity conditions. The subgenus Theriodoros Pospelova-Shtrom 1950 was studied both in Central Asia and Middle East, for the group Pavlovskyella Pospelova-Shtrom 1953, and in Africa and the Mediterranean Basin for the group Theriodoros sensu stricto Pospelova-Shtrom 1953. Within the first group, the biology of O. tholozani was well-documented (Desportes \& Campana, 1946; Balashov, 1972), with a special emphasis on favourable microclimatic conditions for its settlement in Israel and Russian regions, and anthropogenic effects in domestic areas (Avivi, 1967; Vasil'eva et al., 1991; Abidov et al., 1993). Within the second group, Baltazard et al. (1950), Blanc et al. (1951) and Chabaud (1954) have investigated differences in morphology, biology, ecology and vectorial competence between O. erraticus and O. sonrai. Boiron (1949) in Senegal, Hoogstraal (1954) and Khalil et al. (1984) in Egypt and more recently Oleaga-Perez et al. (1990) in Spain studied the effect of climate, soil and host on the settlement patterns in these species in both domestic and wild areas. Recent advances have also been provided by El Shoura (1987) under laboratory conditions. Table II gives an example of optimal and critical climatic conditions defined for several Ornithodoros tick species using these bibliographic resources. As for presence data, information is mainly lacking for American species, with the exception of studies published by Butler (1984), Beck et al. (1986), Adeyeye \& Butler (1989), Adeyeye \& Phillips (1996) and Phillips \& Adeyeye (1996) for O. turicata.

\section{PERSPECTIVES FOR SOFT TICK AND DISEASE MODELLING}

As a first approach for soft ticks, it would be possible to use available presence data in pattern-matching (or statistical or associative) models. These models match observed distributions to various current environment variables in a statistical framework and apply spatial or temporal projected changes in environmental variables, especially climate, to the distribution by interpolation or extrapolation (Kitron \& Mannelli, 1994). Bearing in mind the potential biases of presence datasets, such models enable one to predict a species' range without knowing how each biological parameter is affected by the environment and are easily adapted to risk mapping (Rogers \& Randolph, 2006). However, bibliographic resources on soft ticks remain essential to assess the ecological significance of such models. Another preliminary approach would be to directly use resources on soft tick biology and ecology under specific environmental constraints to implement distribution models. Because available data on soft ticks are heterogeneous according to tick species and the environmental impact of conditions on soft tick survival, development and dynamics are only partially documented, an alternative would be the use of intermediate approaches like fuzzy knowledge-based models (Zadeh, 1965). This approach has been developed for artificial intelligence techniques and is emerging in ecology for predicting species distributional ranges and population dynamics (Bock \& Salski, 1998; Kampichler et al., 2000; Mackinson, 2000; Adriaenssens et al., 2006). It is based on expert or bibliographic knowledge that is represented by a set of logic linguistic rules in the form: IF <premise> THEN < conclusion>, which can be interpreted as a linguistic description of the relationship between environmental conditions and species survival, development or dynamics. The selection of definitive reliable linguistic terms to input into the model is obtained by their combination, according to common optima and/ or limits, obvious interactions between terms and the choice of the most important variables by experts. Available soft tick presence data is then only useful to validate the predictive results of the model. Such a method presents many advantages: $i$ ) it does not suffer from the same biases as presence data; $i$ ) it is based on biological and ecological assertions insuring meaningful predictions; iii) it seems less restrictive than pattern-matching models and enables one to predict potential invasions and adaptations; $i v$ ) it is very malleable with any possible logic rules and any mathematical combinations of rules; $v$ ) it seems optimal to rapidly produce preliminary risk maps for decision makers. However, it may suffer from expert subjectivity and the reliability of bibliographic data. For instance, both methods are currently being tested on Ornithodoros datasets extracted from Morel's publications and the ICTTD database (Vial, personal communication).

In the future, investigations on soft ticks should focus on dynamic approaches instead of static ones, using process-based (or mechanistic or biological) models, 


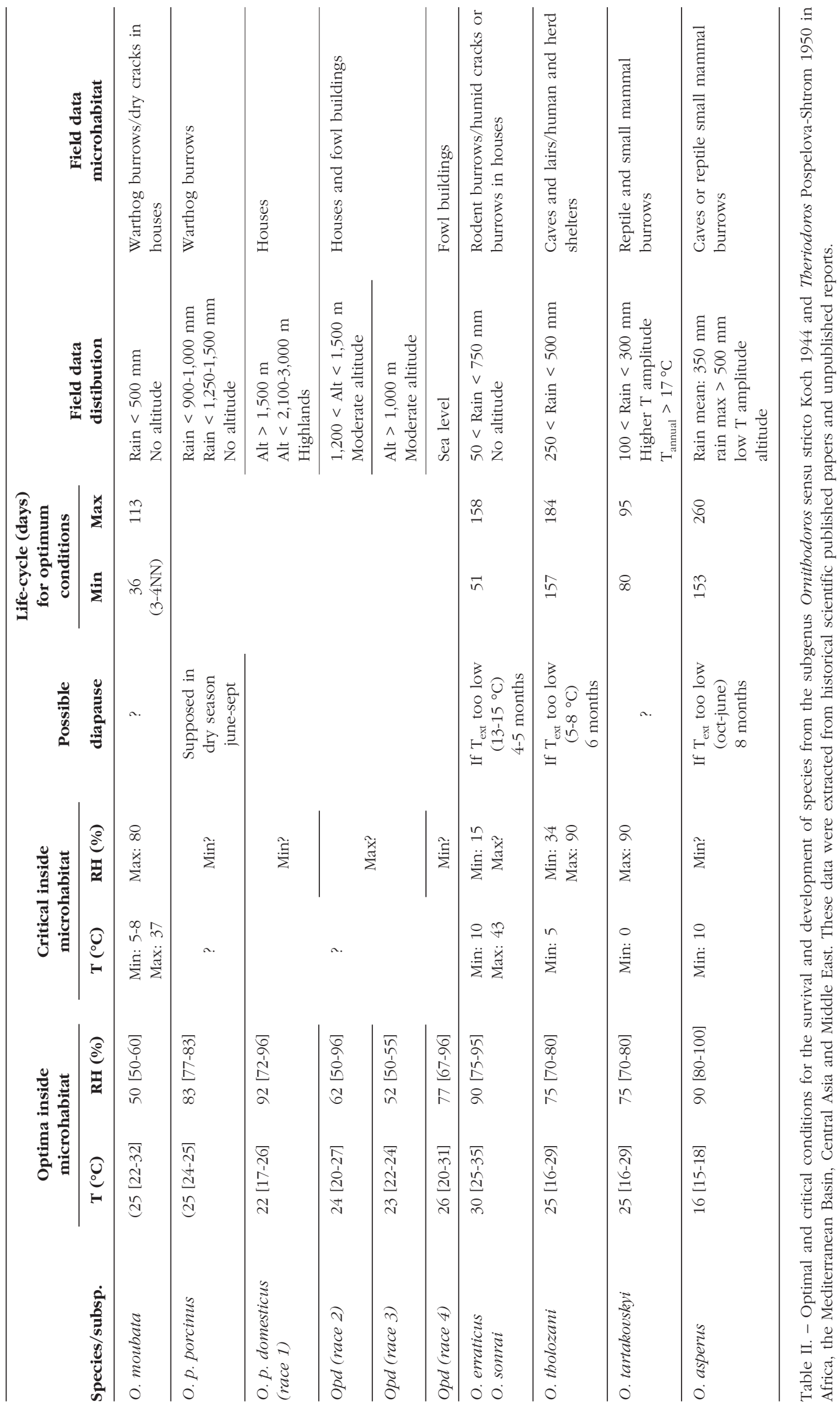


which seek to describe each biological parameter and mechanism underlying a phenomenon and how these aspects can be affected by the environment (Kitron \& Mannelli, 1994). Such approaches are more accurate for modelling complex, weak or temporary processes like seasonal reproduction or blood feeding according to host dynamics (Randolph et al., 2002; Ogden et al., 2005, 2006) and are able to deal with environmental factors other than climate or vegetation, such as anthropogenic effects, landscape uses or species competition/ exclusion (Sumilo et al., 2007). By using equations that describe the growth patterns of a tick population, the infectious status of individuals, their contact with susceptible hosts and host immunity can be easily integrated to obtain disease transmission models (Kitron \& Mannelli, 1994). However, the application of such models to soft ticks will require the collection of detailed biological and ecological data via field and experimental investigations (e.g. life history traits, vectorial competence under variable climates, host preferences and shifts according to abundance or host community composition, human impacts on habitat suitability, etc.) and overcoming the current difficulty of creating risk maps using mathematical models.

\section{CONCLUSION}

This paper reviewed the peculiar biological and ecological characteristics of argasid ticks to be taken into account to enhance predictions concerning soft tick and associated disease distribution, with a special emphasis on Ornithodoros ticks. These characteristics included: $i$ ) nidicolous lifestyle, ii) indiscriminate host feeding and short bloodmeal duration, and iii) flexible developmental cycles via diapause periods. Contrary to the common belief that it may be difficult to predict soft tick distributional patterns according to external measurable environmental data, especially climate, this paper shows that it may be possible, bearing in mind the spatial scale of predictions and the existence of an additional intermediate layer partially buffering external conditions. Host presence seems less important for indiscriminate host feeding soft ticks than for hard ticks. For now, no distributional models have yet been published but investigations are in progress, using pattern-matched models and knowledgebased approaches as promising preliminary studies that can be extended to dynamic process-based models integrating tick-host-pathogen interactions.

\section{ACKNOWLEDGEMENTS}

I

acknowledge Dr Jean-Louis Camicas (IRD, Montpellier) for his assistance in acquisition of bibliogra1 phic knowledge on soft ticks' biology and ecology;
Dr Karen McCoy (CNRS/IRD, Montpellier) for editing the English manuscript; Dr Renaud Lancelot (CIRAD, Montpellier) for institutional support and scientific advices. Some original syntheses presented in the review were supported by the European Centre for Diseases Control and Prevention (ECDC public tender- OJ/ 2007/04/13 - PROC/2007/003) and the European Food Safety Authority (CFP/EFSA/AHAW/2007/02). I gratefully thank the editorial board of Parasite to propose my oral presentation in the CIRDES International Conference, Ouidah Benin 2008, for publication.

\section{REFERENCES}

Abidov Z.I., Vasil’eva I.S., Rakhimov N.R., Gutova V.P. \& ParPIEV A.M. Tick-borne relapsing fever morbidity in Namangan. Meditsinskaia parazitologiia I parazitarnye bolezni, 1993, 1, 32-35.

Adeyeye O.A. \& ButLer J.F. Population structure and seasonal intra-burrow movement of Ornithodoros turicata (Acari: Argasidae) in Gopher tortoise burrows. Journal of Medical Entomology, 1989, 26, 279-283.

Adeyeye O.A. \& Phillips J.S. Photoperiodic response in the soft tick Ornithodoros turicata. International Journal for Parasitology, 1996, 26, 629-635.

Adriaenssens V., Goethals P.L.M. \& De Pauw N. Fuzzy knowledge-based models for prediction of Asellus and Gammarus in watercourses in Flanders (Belgium). Ecolological Modelling, 2006, 195, 3-10.

Avivi A. Biology of the relapsing-fever tick, Ornithodoros tholozani, (Laboulbene \& Megnin, 1882) in Israel. World Health Organization Seminar on the Ecology, Biology and Control of Ticks and Mites of Public Health Importance, 11-15 December 1967, Geneva.

BALASHOV Y.S. Genotypic differences between populations of Ornithodoros tartakovskyi (Ixodoidea, Argasidae) [Russian]. Zoological Zh., 1971, 50, 1795-1802.

BALASHOV Y.S. Bloodsucking ticks (Ixodoidea) vectors of diseases of man and animals. Miscellaneous Publications of the Entomological Society of America, 1972, 8, 161-376.

Baltazard M., Bahmanyar M. \& SAFavi G. Different sizes of Ornithodorus erraticus [French]. Bulletin de la Société de Pathologie Exotique, 1950, XLIII, 444-449.

Blanc G., Chabaud A. \& Bruneau J. Sur les différentes variétés de l'Ornithodorus erraticus. Note préliminaire: Étude de la souche "Balb er Rhob". Bulletin de la Société de Pathologie Exotique, 1951, XXVI, 361-365.

Beck A.F., Holscher K.H. \& ButLer J.F. Life cycle of Ornithodoros turicata americanus (Acari: Argasidae) in the laboratory. Journal of Medical Entomology, 1986, 23, 313-319.

Bock W. \& SAlski A. A fuzzy knowledge-based model of population dynamics of the yellow-necked mouse (Apodemus flavicollis) in beech forest. Ecological Modelling, 1998, 108, 155-161.

Borron H. Comments on tick-borne relapsing fever in Dakar [French]. Bulletin de la Société de Pathologie Exotique, 1949, 42, 13-15. 
Butler J.F., Holscher K.H., Adeyeye O. \& Gibbs E.P.J. Sampling techniques for burrow dwelling ticks in reference to potential African swine fever virus vectors, in: Acarology VI, Vol 2. Griffiths D.A. \& Bowman C.E. (eds), Ellis Horwood, Chichester, 1984, 1065-1074.

Chabaud A. Ornithodorus erraticus (Lucas 1849): diversity of races [French]. Bulletin de la Société de Pathologie Exotique, 1954, XXIV, 89-130.

Cumming G.S. Comparing climate and vegetation as limiting factors for species ranges of African ticks. Ecology, 2002, 83, 255-268.

Cumming G.S. \& VAn VuUren D.P. Will climate change affect ectoparasite species range? Global Ecology and Biogeography, 2006, 15, 486-497.

Cunliffe N. Some observations on the biology of Ornithodoros moubata Murray. Parasitology, 1921, 13, 327-344.

Desportes C. \& Campana Y. On the Ornithodorus tholozani (Laboulbène et Mégnin 1882) and other Ornithodoros species from Central and Minor Asia [French]. Annales de Parasitologie, 1946, XXI, 74-88.

Duplantier J.M., Granjon L. \& BA K. Biogeographic distribution of rodents in Senegal [in French]. Journal of African Zoology, 1997, 111, 17-26.

EL SHOURA S.M. Effect of temperature and relative humidity on the life cycle of Ornithodoros (Pavlovskyella) erraticus (Ixodoidea: Argasidae). The Journal of Parasitology, 1987, 73, 1102-1108

Endris R.G., Haslett T.M., Monahan M.J. \& Phillips J.G. Laboratory Biology of Ornithodoros (Alectorobius) puertoricensis (Acari: Argasidae). Journal of Medical Entomology, 1991, 28, 49-62.

Gaber M., Khalil G., Hoogstraal H. \& Aboul-Nasr A. Borrelia crocidurae localization and transmission in Ornithodoros erraticus and O. savignyi. Parasitology, 1984, 88, 403413.

Gugushvili G.K. Amphibian and reptile hosts of Ornithodoros verrucosus and Ornithodoros alactagalis populations in natural biotopes of Georgian USSR [Russian]. Soobshch. Akad. Nauk Gruz. SSR, 1980, 98, 453-456.

Hafez M., Abdel-MaleK A.A. \& Guirgis S.S. The subgenus Persicargas (Ixodoidea: Argasidae: Argas). 12. Biological studies on the immature stages of $A$. (P.) arboreus Kaiser, Hoogstraal and Kohls in Egypt. Journal of Medical Entomology, 1971, 8, 421-429.

Heger T., Guerin P. \& Eugster W. Microclimatic factors influencing refugium suitability for Rodnius prolixus. Physiological Entomology, 2006, 31, 248-256.

Hoogstraal H., Salah A.A. \& Kaiser M.N. Summary of the known distribution of Ornithodoros erraticus (Lucas, 1849) (Ixodidae, Argasidae) in Egypt. The Journal of the Egyptian Public Health Association, 1954, XXIX, 127-138.

Hoogstraal H. Argasid and Nuttalliellid ticks as parasites and vectors. Advances in Parasitology, 1985, 24, 135-238.

Hutchinson G.E. "Concluding remarks". Cold Spring Harbor Symposia on Quantitative Biology, 1957, 22, 415-427.

Jobling B. A contribution to the biology of Ornithodoros moubata Murray. Bulletin of Entomological Research, 1925, 15, 271-280.
Jonjegan F. \& Uilenberg G. The global importance of ticks. Parasitology, 2004, 129, S3-S14.

Kampichler C., Barthel J. \& Wieland R. Species density of foliage-dwelling spiders in field margins: a simple, fuzzy rule-based model. Ecological Modelling, 2000, 129, 87-99.

KENT R.J. Molecular methods for arthropod bloodmeal identification and applications to ecological and vector-borne disease studies. Molecular Ecology Resources, 2009, 9, 4-18.

Khalil G.M. The subgenus Persicargas (Ixodoidea: Argasidae: Argas). 19. Preliminary studies on diapause in A. (P.) arboreus Kaiser, Hoogstraal \& Kohls. Journal of Medical Entomology, 1974, 11, 363-366.

Khalil G.M. \& Shanbaky. The subgenus Persicargas (Ixodoidea: Argasidae: Argas). 25. Effect of temperature on diapause termination in female A. (P.) arboreus Kaiser, Hoogstraal \& Kohls. Experimental Parasitology, 1976, 39, 431-437.

Khalil G., Helmy N., Hoogstraal H. \& El-Said A. Seasonal dynamics of Ornithodoros (Pavlovskyella) erraticus (Acari: Ixodoidea: Argasidae) and the spirochete Borrelia crocidurae in Egypt. Journal of Medical Entomology, 1984, 21, 536-539.

Kitron U. \& Mannelui A. Modeling the ecological dynamics of tick-borne zoonoses, in: Ecological dynamics of tickborne zoonoses. Sonenshine D.E. \& Mather T.N. (eds), Oxford University Press, Oxford, 1994, 198-239.

Kleiboeker S.B., Burrage T.G., Scoles G.A., Fish D. \& Rock D.L. African swine fever virus infection in the Argasid host, Ornithodoros porcinus porcinus. Journal of Virology, 1998, 72, 1711-1724.

LEES A.D. Transpiration and structure of the epicuticle in ticks. The Journal of experimental Biology, 1947, 23, 379-410.

Loomis E.C. Life histories of ticks under laboratory conditions (Acarina: Ixodidae and Argasidae). Journal of Parasitology, 1961, 47, 91-99.

MaCKINSON S. An adaptive fuzzy expert system for predicting structure, dynamics and distribution of herring shoals. Ecological Modelling, 2000, 126, 155-178.

McCall P.J., Hume J.C., Motshegwa K., Pignatelli P., Talbert A. \& KISINZA W. Does tick-borne relapsing fever have an animal reservoir in East Africa? Vector Borne and Zoonotic Diseases, 2007, 20.

McMichael A.J., Woodruff R.E. \& Hales S. Climate change and human health: present and future risks. The Lancet, 2006, 367, 859-869.

Morel P.C. Ticks from Africa and the Mediterranean Bassin [French], 1969, Published by CIRAD in 2003, CDROM.

Moskvin I.A. The role of Ornithodoros papillipes Birula ticks in the transmission of relapsing typhus [Russian]. C. R. AC. SC. URSS, 1927, XXII, 375.

Ogden N.H., Bigras-Poulin M., O'Callaghan C.J., Barker I.K., Lindsay L.R., MaArouf A., SMOYer-Tomic K.E., WaltnerToews D. \& Charron D. A dynamic population model to investigate effects of climate on geographic range and seasonality of the tick Ixodes scapularis. International Journal for Parasitology, 2005, 35, 375-339.

Ogden N.H., MaArouf A., Barker I.K., Bigras-Poulin M., LindSay L.R., Morshed M.G., O'Callaghan C.J., Ramay F., WalTNer-Toews D. \& Charron D.F. Climate change and the 
potential for range expansion of the Lyme disease vector Ixodes scapularis in Canada. International Journal for Parasitology, 2006, 36, 63-70.

Oleaga-Pérez A., Pérez-Sanchez R. \& Encinas-Grandes A. Distribution and biology of Ornithodoros erraticus in parts of Spain affected by African swine fever. The Veterinary Record, 1990, 126, 32-37.

Olmedo F.F., Estrada-Pena A. \& Espuny J.C. Variations in the size and weight of adults of Ornithodoros marocanus Velu (Acari: Argasidae) according nymphal blood-intake. Acarologia, 1995, XXXVI, 195-201.

PAvlovsky E.N. Natural Nidality of Transmissable Diseases, University of Illinois Press, Urbana, Illinois, 1966.

Phillips J.S. \& ADEYEYE O.A. Reproductive bionomics of the soft tick, Ornithodoros turicata (Acari: Argasidae). Experimental and Applied Acarology, 1996, 20, 369-380.

PIERCE M.A. Distribution and ecology of Ornithodoros moubata porcinus Walton (Acarina) in animal burrows in East Africa. Bulletin of Entomological Research, 1974, 64, 605619.

Pospelova-Shtrom M.V. Ornithodorini ticks and the epidemiological significance [Russian]. Moscow, 1953, 235 p.

Pospelova-Shtrom M.V. On the system of classification of ticks of the family Argasidae CAN., 1890. Acarologia, 1969, XI.

Randolph S.E., Green R.M., Hoodless A.N. \& Peacey M.F. An empirical quantitative framework for the seasonal population dynamics of the tick Ixodes ricinus. International Journal for Parasitology, 2002, 32, 979-989.

Rogers D.J. \& RANDOLPH S.E. Climate change and vector-borne diseases. Advances in Parasitology, 2006, 62, 345-381.

SONENShine D.E. \& AnAstos G. Observations on the life history of the bat tick Ornithodoros kelleyi (Acarina: Argasidae). Journal of Parasitology, 1960, 46, 449-454.

SONENSHINE D.E. Ecology of nidicolous ticks, in: Biology of ticks, Vol. 2. Oxford University Press, New York, 1993, 465 p.

Sumilo D., Asokliene L., Bormane A., Vasilenko V., GolovlJOVA I. \& Randolph S. Climate change cannot explain the upsurge of tick-borne encephalitis in the baltics. PLOS ONE, 2007, 2 (6), e500.

Trape J.F., Godeluck B., Diatta G., Rogier C., Legros F., AlberGel J., Pépin Y. \& Duplantier J.M. Tick-borne borreliosis in West Africa: recent epidemiological studies. Roczniki Akademii Medycznej w Bialymstoku, 1996, 41, 136-141.

VASIL'EVA I.S. Contribution to the problem of hosts of Alectorobius tartakovskyi ticks. III. Factors determining the role of different animal species in feeding of tick populations [Russian]. Meditsinskaia parazitologiia I parazitarnye bolezni, 1971, 40, 577-581.

Vasil'eva I.S., ERshova A.S., Mansurov A.A., Andrianov V.A., Abidov Z.I., IBragimov I.U.I. \& NARMATOV N.N. Changes in the village foci of tick-borne relapsing fever in Uzbekistan over a 10-year period [Russian]. Parazitologiia, 1991, 25 , 323-329.

VIAL L. Eco-epidemiology of tick-borne relapsing fever caused by Borrelia crocidurae in West Africa [French]. PhD Thesis. Montpellier II University Science and Technology, Languedoc, 2005, 236 p.
Vial L., Diatta G., Tall A., Ba E., Bouganali H., Durand P., Sokhna C., Rogier C., Renaud F. \& Trape J.F. Incidence of tick-borne relapsing fever in West Africa: longitudinal study. The Lancet, 2006a, 368, 37-43.

Vial L., Durand P., Arnathau C., Halos L., Diatta G., Trape J.F. \& RENAUd F. Molecular divergences of the Ornithodoros sonrai soft tick species, a vector of human relapsing fever in West Africa. Microbes and Infections, 2006b, 8, 26052611.

Vial L., Wieland B., Jori F., Etter E., Dixon L. \& Roger F. African swine fever virus DNA in soft ticks, Senegal. Emerging Infectious Diseases, 2007, 13, 1928-1931.

Walton G.A. The Ornithodoros moubata subspecies problem in relation to human relapsing fever epidemiology. Symposium of Zoological Society of London, 1962, 6, 83-156.

Walton G.A. The Ornithodorus "moubata" group of ticks in Africa: Control problems and implications. Journal of Medical Entomology, 1964, 1, 53.

Walton G.A. A taxonomic review of the Ornithodoros moubata (Murray) 1877 (sensu Walton, 1962) species group in Africa, in: Recent Advances in Acarology, Vol. II. Academic Press (eds), 1979, 491-500.

WHEELER C. M. A contribution to the biology of Ornithodoros hermsi Wheeler, Herms and Meyer. Journal of Parasitology, 1943, 29, 33-41.

YunKER C.E. \& GuIRGIS S. Studies of rodent burrows and their ectoparasites in the Egyptian desert. 1. Environment and microenvironment: some factors influencing acarine distribution. The Journal of the Egyptian Public Health Association, 1970, XLIV, 498-542.

ZADEH L.A. Fuzzy sets. Information Control, 1965, 8, 338-353.

Reçu le 9 avril 2009 Accepté le 25 juin 2009 